\title{
Potential application of gold nanoparticles in food packaging: a mini review
}

\author{
Saeed Paidari ${ }^{1} \cdot$ Salam Adnan Ibrahim ${ }^{2}$ (D) \\ Received: 2 October 2020 / Accepted: 5 January 2021 / Published online: 20 February 2021 \\ (C) This is a U.S. government work and not under copyright protection in the U.S.; foreign copyright protection may apply 2021
}

\begin{abstract}
In the past few decades, there have been remarkable advances in our knowledge of gold nanoparticles (AuNPs) and synthesizing methods. AuNPs have become increasingly important in biomedical and industrial applications. As a newly implemented method, AuNPs are being used in nanopackaging industries for their therapeutic and antibacterial characteristics as well as their inert and nontoxic nature. As with other NPs, AuNPs have privileges and disadvantages when utilized in the food sector, yet a significant body of research has shown that, due to the specific nontoxic characteristics, AuNPs could be used to address other NP flaws. In this mini review, we present synthesizing methods, food industry applications, and mechanisms of action of gold nanoparticles. Regarding the investigations, gold nanoparticles can play a major role to reduce microbial load in foodstuff and therefore can be implemented in food packaging as an effective approach.
\end{abstract}

Keywords Gold nanoparticle $\cdot$ AUNPs $\cdot$ Nanopackaging $\cdot$ Antimicrobial $\cdot$ Synthesize

\section{Introduction}

As a precious substance, gold has been highly regarded throughout human history [1]. Because gold atoms possess very unique and special characteristics, the chemistry of gold has garnered remarkable attention. In addition to the application of gold in cosmetics, jewelry, dentistry, and, of course, as money, gold has been widely used for medicinal, material sciences and catalysis purposes over the years [2-4]. For example, more recently, gold compounds have been used as antibacterial agents and antifungals against a wide spectrum of microbes. In addition to the antimicrobial and antifungal characteristics of gold compounds, antiamoebic, antileishmenic, and antitrypanosomical activity has been proven $[5,6]$. Numerous gold compounds with various ligands such as phosphine type ligands and N-heterocyclic-L-

Salam Adnan Ibrahim

ibrah001@ncat.edu

1 Department of Food Science and Technology, Science and Research Branch, Islamic Azad University, Tehran, Iran

2 Food Microbiology and Biotechnology Laboratory, 173 Carver Hall, North Carolina Agricultural and Technical State University, Greensboro, NC 27411, USA cysteine as well as chloroquine have been used as antimicrobial agents against a wide array of microbes [7].

In recent years, there has been significant interest on application of packaging containing different nanoparticles due to the effects on shelf life, gas barrier properties, and mechanical characteristics [8-10]. Additionally, the effects of NPs on inhibition of bacterial growth have led to further research on evaluation of the size, shape, and concentration of applied NPs in packaging [11-13]. Depending on the foodstuff, the type of packaging matrix is of great importance. The addition of metal NPs such as silver, cooper, $\mathrm{TiO}_{2}$, and gold to polymer matrices, mechanical properties, thermal resistance, gas barrier properties, and antimicrobial properties is considered to be improved in comparison with the usual polymers [14, 15]. Moreover some of these NPs increase the packaging resistance such as thermal and mechanical resistance under high pressure. Examples of these coatings for foodstuff include antifungal-coated packaging for cherries, silver-zeolite antibacterial packaging for raw meat, and antioxidant coating used for mushrooms $[6,16]$.

Although silver NPs have gained much more applications in the food industry, with respect to some unique characteristics of gold NPs, these kind of packaging can be implemented in specific portions of food industry[17, 18]. D AuNPs have received considerable interest in both the medical and food packaging industries due to therapeutic activity, the inert and 
nontoxic nature of gold NPs, and oxidative catalytic characteristics $[15,18]$. Nanotechnology applications in the food industry such as the migration of NPs into foodstuff can help to reduce the incidence of foodborne pathogens [19]. The high surface to volume ratio of AuNPs increases their reaction with biomolecules and bacterial cell bonds and, eventually, bacterial deterioration occurs $[20,21]$. In the following section, we have provided some points on syntheses and mechanism of action of gold NPs with respect to their potential application in the food industry.

\section{Synthesis of AuNPs}

A wide array of methods has been suggested for synthesizing AuNPs with controlled size, shape, functionality, and surface area. Turkevich et al. synthesized AuNPs using HAucl4 and citric acid at $100{ }^{\circ} \mathrm{C}[22]$. Other researchers tried to further develop this method by changing the reducing agent $[16,18$, 21]. The size of NPs produced by the Turkevich method was 10-20 nm, though larger NPs can be synthesized by this method. The utilization of citrate in synthesis of gold nanoparticles can lead to agglomeration of nanoparticles. As a result, numerous methods have been developed to address this issue using different solutions such as Tween 20, thiolic acid, and various surfactants [15].

In 1994, Brust et al. conducted a study on the application of thiolic groups to produce non-aggregate and redispensable solutions of AuNPs [23]. More recently, in green synthesis of nanoparticles, different reducing agents have been used to synthesize AuNPs [24-26]. Synthesis of gold NPs generally can be achieved by two different methods: (a) producing NPs from bulk gold and (b) synthesizing gold NPs using atomic steps [25, 27]. Aerosol technology, UV radiation reduction, and laser ablation are also famous methods. However, among the aforementioned methods, chemical reduction has gained much more attention due to its lower expense on simple instrumentation. According to Fig. 1, the general reduction method involves two steps $[11,28]$ :

(1) Reduction of the gold salt solution using reducing agent such as citrate and borohydrate

(2) Preventing agglomeration of AU particles through using stabilizing agents

Changing the size, shape, and morphology of NPs leads to different characteristics, so researchers have paid much more attention to synthesizing gold NPs of other shapes such as nanorods, nanocubes, and triangular NPs [17, 25].

\section{Antimicrobial characteristics}

Gold nanoparticles can be evaluated from various aspects such as antibacterial, antifungal, and anticancer. Additionally, AuNP complexes such as those with antibiotics and chemicals have been investigated widely [29, 30]. Tables 1 and 2 indicate that numerous studies have been conducted to evaluate the antimicrobial characteristics of AuNPs synthesized through different methods such as chemical reduction and green synthesizing as well as incorporation of AuNPs with other NPs. Some of these novel studies are discussed below.

A number of researchers evaluated the antifungal effects of AuNPs synthesized through chemical as well as green
Fig. 1 Synthesizing of AuNPs by reduction of $\mathrm{HAuCl}_{4}$ and $\mathrm{NaBH}_{4}$ as reducing agent

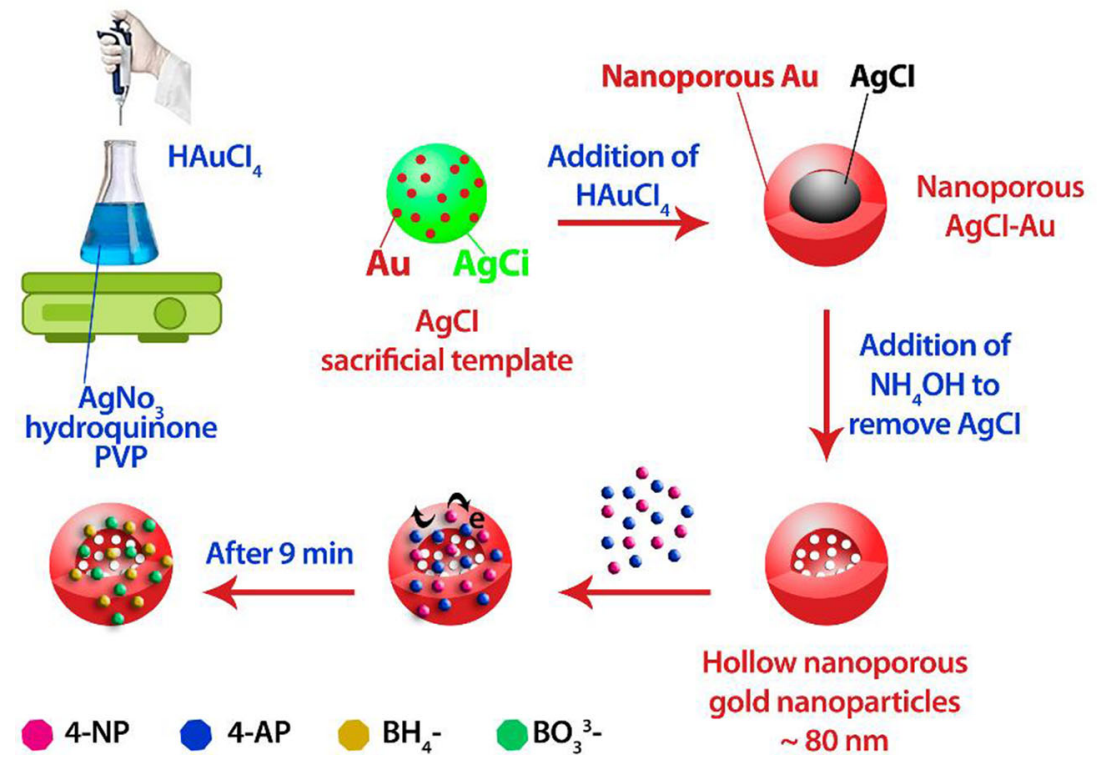


Table 1 Antibacterial effects of AuNPs against $E$. coli

\begin{tabular}{lllll}
\hline & Size & Matrix, ligand & Effectiveness & Reference \\
\hline 1 & $15-35 \mathrm{~nm}$ & Green synthesize phytochemicals & Effective & {$[31]$} \\
2 & $1-22$ & CTAB & Highly effective & {$[32]$} \\
3 & $80-100 \mathrm{~nm}$ & C. zeylanicum lead & Effective & {$[33]$} \\
4 & $15-25 \mathrm{~nm}$ & Mumbellatum extract & Effective $(200 \mu \mathrm{g} / \mu \mathrm{l})$ & {$[34]$} \\
5 & $5-12 \mathrm{~nm}$ & Shewanella oneidensis & Not effective & {$[35]$} \\
6 & $6-70 \mathrm{~nm}$ & E. hirta L. & Effective & {$[36]$} \\
7 & $25-60-120$ & Dextrose & Effective & {$[37]$} \\
8 & $33-65 \mathrm{~nm}$ & T. decandra & Effective & {$[38]$} \\
9 & $5 \mathrm{~nm}$ & Chemical reduction & Not effective & {$[39]$} \\
10 & $150 \mathrm{~nm}$ & Mentha piperita & Effective & {$[40]$} \\
\hline
\end{tabular}

methods against prevalent human pathogens such as Candida albicans. According to the literature, strong antifungal effects of AuNPs have been proved, with size, shape, and concentration being the primary determinants of fungicidal effects [47]. Wani and Ahmad conducted a study to evaluate synthesized polyhedrons and disks of gold nanoparticles $(25-30 \mathrm{~nm})$. The results showed high antifungal activity against Candida albicans. Moreover, higher antifungal effects were reported for nanodisks in comparison with polyhedral AuNPs (Table 1). Likewise, Nidhin et al. (2019) investigated the effects of $5 \mathrm{~nm}$ AuNPs against $C$. albicans. MIC results revealed that a $0.5 \mathrm{mM}$ concentration was highly effective against C. albicans [54].

The antibacterial effects of AuNPs are a controversial topic. Although numerous researchers have reported high antibacterial effects of gold NPs [32, 33], others have stated that AuNPs have no effect on the reduction of bacterial loads. According to skeptics, the reported antibacterial results from other researchers are probably due to chemical agents that are bonded to the surface of AuNPs [39, 55]. Rajathi et al. (2012) investigated the application of Stoechospermum marginatum for synthesizing AuNPs. In this study, $1 \mathrm{~g}$ of $S$. marginatum was mixed with $100 \mathrm{ml} \mathrm{HAuCl}_{4}$ to produce $40-80 \mathrm{~nm}$

Table 2 Antibacterial effects of AuNPs against $S$. aureus

\begin{tabular}{lllll}
\hline & Size & Matrix, ligand & Effectiveness & Reference \\
\hline 1 & $80 \mathrm{~nm}$ & PVP & Effective $(200 \mu \mathrm{g} / \mu \mathrm{l})$ & {$[41]$} \\
2 & $4-8 \mathrm{~nm}$ & Polyamidamine & Effective $(2 \mu \mathrm{g} / \mu \mathrm{l})$ & {$[30]$} \\
3 & $\mathrm{~nm}$ & Phosphine & Effective & {$[42]$} \\
4 & $150 \mathrm{~nm}$ & Mentha piperita & Not effective & {$[40]$} \\
5 & $1-3 \mathrm{~nm}$ & Cationic peptide & Effective & {$[43]$} \\
6 & $33-65 \mathrm{~nm}$ & T. decandra & Effective & {$[38]$} \\
7 & $\mathrm{~nm}$ & Tinctorius flower & Effective & {$[44]$} \\
8 & $\mathrm{~nm}$ & Chinensis & Effective & {$[45]$} \\
9 & $5-30 \mathrm{~nm}$ & Euphorbia hirta L. & Effective $(512 \mu \mathrm{g} / \mu \mathrm{l})$ & {$[36]$} \\
10 & $\mathrm{~nm}$ & Grapefruit & Effective & {$[46]$} \\
\hline
\end{tabular}

AuNPs. According to the results, 95\% of bioreduction occurred during the first $12 \mathrm{~h}$ of reaction. A UV-Vis spectrum (300-800 nm) was used for recording the light absorbance spectrum. In addition, TEM, FTIR, and FESEM analyses were carried out for further examination of the size and morphology of produced NPs. Then, the antibacterial effects of AuNPs were evaluated against Pseudomonas aeruginosa, Klebsiella oxytoca, Enterobacter faecalis, Klebsiella pneumonia, Salmonella typhimurium, and Proteus vulgaris. The results demonstrated that produced AuNPs were highly bactericidal against $K$. pneumonia although no inhibition zone was recorded for $E$. coli [56].

In a study conducted by Emam et al. (2017), $\mathrm{H}_{2} \mathrm{O}_{2}$ was used as an enhancer for reducibility of starch as a reducing agent for synthesizing AuNPs. MIC (960 $\mu \mathrm{l} / \mathrm{ml})$ results showed that synthesized AuNPs (40-80 nm) were significantly bactericidal against $S$. aureus samples [25].

Kurtjak et al. (2017) investigated the antimicrobial effects of AuNPs (10-15 nm) functionalized with arginine and hydroxyapatite containing $\mathrm{Ga}^{3+}$ ions. Results showed that AuNPs had antibacterial effects against $E$. coli and $S$. aureus, while disk diffusion results did not exhibit any inhibition zone against the $P$. aeruginosa MW1 strain. However, AuNPs $+\mathrm{Ga}^{3+}$ NPs could significantly reduce bacterial loads in the samples $(p<0.01)$ [16]. On the contrary, Grace et al. (2006) studied the effects of aminoglycosidic antibiotic-protected gold nanoparticles. The results revealed that gold nanoparticles acted as a proper carrier of nanoparticles due to the high surface to volume ratio. However, the nanoparticles did not have any independent antibacterial effects against $S$. aureus, Micrococcus luteus, and Pseudomonas aeruginosa using the inhibition zone method [21]. This could probably be due to the higher size of AuNPs $(85 \mathrm{~nm})$ in comparison with that of Kurtjak et al. [16].

Ramakritina et al. (2013) evaluated the effects of PVAAuNPs composites against both Gram negative and Gram positive (E. coli and $S$. aureus) bacteria. Results showed that green synthesized Phyllanthus emblica could exert a $1 \mathrm{~cm}$ inhibition zone in $24 \mathrm{~h}(p<0.01)$ [18]. In comparison with 
Table 3 Antifungal activity of AuNAPs and gold complex

\begin{tabular}{lllll}
\hline \multicolumn{2}{l}{ Type } & Size & Effectiveness & Reference \\
\hline 1 & Candida spp. & $7-15 \mathrm{~nm}$ & Highly effective & {$[48]$} \\
2 & Candida spp. & $25-30$ (nano-disk polyhedral) & Effective & {$[49]$} \\
3 & P. graminis & $45-75 \mathrm{~nm}$ & Effective & {$[50]$} \\
4 & Candida albicans & $45-75 \mathrm{~nm}$ & Effective & {$[50]$} \\
5 & C. albicans ATCC 70231 & $36-74 \mathrm{~nm}$ & Effective & {$[38]$} \\
6 & C. albicans MTCC 1833 & $18-80 \mathrm{~nm}$ & Effective & {$[51]$} \\
7 & Candida spp. & Gold phosphine complex & Effective & {$[52]$} \\
8 & Cryptococcus spp. & Gold phosphine complex & Effective & {$[52]$} \\
9 & Aspergillus spp. & Gold phosphine complex & Effective & {$[52]$} \\
10 & Candida spp. & $5 \mathrm{~nm}$ & Effective & {$[53]$} \\
\hline
\end{tabular}

Significance of row 1: $P<0.01$

Significance of other rows: $P<0.05$
Nirmala, a lower size ( $2-4 \mathrm{~nm}$ ) of produced AuNPs could be the reason of this significant difference in the bactericidal effect. Likewise, Nazari et al. reported that no inhibition zone was proved for Pseudomonas aeruginosa using AuNP disks $(2-100 \mathrm{~nm})$ [57].

\section{Mechanism of action}

In opposite of silver nanoparticles as far as we surveyed, to date, little studies have been conducted on evaluating the mechanism of action of sole gold nanoparticles against different bacteria and they were evaluated capped with other agents and chemicals. However, according to nanoscience, the transformation of molecules to nanoparticles leads to different effects. Among them, increasing the surface to volume ratio [11], existence of $\mathrm{Au}$ ions in the environment of bacterial cells, and production of radical oxygen are probably the main reasons of antibacterial mechanism of gold nanoparticles [58]. Li reported that synthesized AuNPs could significantly interact with both Gram negative and Gram positive bacteria resulting in the formation of aggregation patterns that lead to lysis of microbial cells [11].

\section{Conclusion}

Nanotechnology has opened new horizons in a variety of research area applications including the food sector. Implementation of AuNPs in coatings and packaging has been a controversial issue as most scientists believe that AuNPs along with many other NPs can exert antimicrobial effects on pathogenic organisms. A wide range of Gram negative and Gram positive bacteria have been examined, among which $E$. coli has been the most controversial. Although the size and morphology of NPs are important criteria, the synthesizing method and reducing agent may also affect the results. The application of gold nanoparticles is thus highly suggested as antibacterial agents for high-end, luxury products such as caviar.

Funding Author SAI would like to acknowledge the support of the Agricultural Research Station at North Carolina Agricultural and Technical State University (Greensboro, NC 27411, USA). This research was funded, in part, by grants (project numbers NC.X337-5-21-170-1 and NC.X341-5-21-170-1) from the National Institute of Food and Agriculture (NIFA).

\section{Compliance with ethical standards}

Conflict of interest The authors declare that they have no conflict of interest.

Disclaimer Its contents are solely the responsibility of the authors and do not necessarily represent the official views of NIFA.

Open Access This article is licensed under a Creative Commons Attribution 4.0 International License, which permits use, sharing, adaptation, distribution and reproduction in any medium or format, as long as you give appropriate credit to the original author(s) and the source, provide a link to the Creative Commons licence, and indicate if changes were made. The images or other third party material in this article are included in the article's Creative Commons licence, unless indicated otherwise in a credit line to the material. If material is not included in the article's Creative Commons licence and your intended use is not permitted by statutory regulation or exceeds the permitted use, you will need to obtain permission directly from the copyright holder. To view a copy of this licence, visit http://creativecommons.org/licenses/by/4.0/.

\section{References}

1. Dasari TS, Zhang Y, Yu H (2015) Antibacterial activity and cytotoxicity of gold (I) and (III) ions and gold nanoparticles. Biochem Pharmacol: Open Access 4(6) 
2. Rao BL, Gowda M, Asha S, Byrappa K, Narayana B, Somashekar R, Wang Y, Madhu L, Sangappa Y (2017) Rapid synthesis of gold nanoparticles using silk fibroin: characterization, antibacterial activity, and anticancer properties. Gold Bull 50(4):289-297

3. Corti CW, Holliday RJ (2004) Commercial aspects of gold applications: from materials science to chemical science. Gold Bull 37(1-2):20-26

4. Hashmi ASK, Hutchings GJ (2006) Gold catalysis. Angew Chem Int Ed 45(47):7896-7936

5. Grade S, Eberhard J, Jakobi J, Winkel A, Stiesch M, Barcikowski S (2014) Alloying colloidal silver nanoparticles with gold disproportionally controls antibacterial and toxic effects. Gold Bull 47(1-2):83-93

6. Ahari H, Karim G, Anvar SA, Paidari S, Mostaghim SA, Mazinani AS (2020) Method for producing antimicrobial nanofilms packaging cover based on titanium nano-dioxide through extrusion for extension of food shelf-life. Google Patents

7. Glišić BĐ, Djuran MI (2014) Gold complexes as antimicrobial agents: an overview of different biological activities in relation to the oxidation state of the gold ion and the ligand structure. Dalton Trans 43(16):5950-5969

8. Paidari S, Goli M, Anari ES, Haghdoust NS (2019) Evaluation the effects of nanosilver composites synthesized using sol-gel method on inoculated Vibrio parahaemolyticus to pink shrimp. Acta Sci Nutr Health 3(2):47-51

9. Hosseini R, Ahari H, Mahasti P, Paidari S (2017) Measuring the migration of silver from silver nanocomposite polyethylene packaging based on (TiO 2) into Penaeus semisulcatus using titration comparison with migration methods. Fish Sci 83(4):649-659

10. Eddin AS, Ibrahim SA, Tahergorabi R (2019) Egg quality and safety with an overview of edible coating application for egg preservation. Food Chem 296:29-39

11. Li X, Robinson SM, Gupta A, Saha K, Jiang Z, Moyano DF, Sahar A, Riley MA, Rotello VM (2014) Functional gold nanoparticles as potent antimicrobial agents against multi-drug-resistant bacteria. ACS Nano 8(10): 10682-10686

12. Singh S, Dev A, Gupta A, Nigam VK, Poluri KM (2019) Nitrate reductase mediated synthesis of surface passivated nanogold as broad-spectrum antibacterial agent. Gold Bull 52(3):197-216

13. Issa A, Ibrahim S, Tahergorabi R (2016) Sweet potato starch/clay nanocomposite film: new material for emerging biodegradable food packaging. MOJ Food Processing. Technology 3(3):00073

14. Anvar A, Haghighat Kajavi S, Ahari H, Sharifan A, Motallebi A, Kakoolaki S, Paidari S (2019) Evaluation of the antibacterial effects of Ag-Tio2 nanoparticles and optimization of its migration to sturgeon caviar (Beluga). Iran J Fish Sci 18(4):954-967

15. Yeh Y-C, Creran B, Rotello VM (2012) Gold nanoparticles: preparation, properties, and applications in bionanotechnology. Nanoscale 4(6):1871-1880

16. Kurtjak M, Vukomanović M, Suvorov D (2017) Antibacterial nanocomposite of functionalized nanogold and gallium-doped hydroxyapatite. Mater Lett 193:126-129

17. Sahoo G, Sarkar N, Swain SK (2017) Antimicrobial properties of nanogold-imprinted starch bionanocomposites. Polym-Plast Technol Eng 56(3):334-345

18. Ramakritinan C, Kaarunya E, Shankar S, Kumaraguru A (2013) Antibacterial effects of $\mathrm{Ag}, \mathrm{Au}$ and bimetallic (Ag-Au) nanoparticles synthesized from red algae. In: Solid State Phenomena. Trans Tech Publ, R (Vol. 201), pp 211-230

19. Zhou Y, Kong Y, Kundu S, Cirillo JD, Liang H (2012) Antibacterial activities of gold and silver nanoparticles against Escherichia coli and bacillus Calmette-Guérin. J Nanobiotechnol 10(1):19

20. Jahadi M, Ehsani M, Paidari S (2018) Characterization of milk proteins in ultrafiltration permeate and their rejection coefficients. J Food Biosci Technol 8(2):49-54
21. Grace AN, Pandian K (2007) Antibacterial efficacy of aminoglycosidic antibiotics protected gold nanoparticles - a brief study. Colloids Surf A Physicochem Eng Asp 297(1-3):63-70

22. Kimling J, Maier M, Okenve B, Kotaidis V, Ballot H, Plech A (2006) Turkevich method for gold nanoparticle synthesis revisited. J Phys Chem B 110(32):15700-15707

23. Brust M, Walker M, Bethell D, Schiffrin DJ, Whyman R (1994) Synthesis of thiol-derivatised gold nanoparticles in a two-phase liquid-liquid system. J Chem Soc Chem Commun (7):801-802

24. Muthuvel A, Adavallan K, Balamurugan K, Krishnakumar N (2014) Biosynthesis of gold nanoparticles using Solanum nigrum leaf extract and screening their free radical scavenging and antibacterial properties. Biomed Prev Nutr 4(2):325-332

25. Emam HE, Zahran M, Ahmed HB (2017) Generation of biocompatible nanogold using $\mathrm{H} 2 \mathrm{O} 2-$ starch and their catalytic/ antimicrobial activities. Eur Polym J 90:354-367

26. Balasubramanian K (2014) Antibacterial application of polyvinyl alcohol-nanogold composite membranes. Colloids Surf A Physicochem Eng Asp 455:174-178

27. Abdel-Raouf N, Al-Enazi NM, Ibraheem IB (2017) Green biosynthesis of gold nanoparticles using Galaxaura elongata and characterization of their antibacterial activity. Arab J Chem 10:S3029 S3039

28. Saha K, Agasti SS, Kim C, Li X, Rotello VM (2012) Gold nanoparticles in chemical and biological sensing. Chem Rev 112(5): 2739-2779

29. Zharov VP, Mercer KE, Galitovskaya EN, Smeltzer MS (2006) Photothermal nanotherapeutics and nanodiagnostics for selective killing of bacteria targeted with gold nanoparticles. Biophys J 90(2):619-627

30. Zhang Y, Peng H, Huang W, Zhou Y, Yan D (2008) Facile preparation and characterization of highly antimicrobial colloid Ag or Au nanoparticles. J Colloid Interface Sci 325(2):371-376

31. Lima E, Guerra R, Lara V, Guzmán A (2013) Gold nanoparticles as efficient antimicrobial agents for Escherichia coli and Salmonella typhi. Chem Cent J 7(1):11

32. Nagaraj B, Divya T, Krishnamurthy N, Dinesh R, Negrila C, Predoi D (2012) Phytosynthesis of gold nanoparticles using Caesalpinia pulcherrima (peacock flower) flower extract and evaluation of their antimicrobial activities. Dig J Nanomater Biostruct (DJNB) 7(3)

33. Smitha S, Gopchandran K (2013) Surface enhanced Raman scattering, antibacterial and antifungal active triangular gold nanoparticles. Spectrochim Acta A Mol Biomol Spectrosc 102:114-119

34. Arunachalam KD, Annamalai SK, Hari S (2013) One-step green synthesis and characterization of leaf extract-mediated biocompatible silver and gold nanoparticles from Memecylon umbellatum. Int J Nanomedicine 8:1307

35. Suresh AK, Pelletier DA, Wang W, Broich ML, Moon J-W, Gu B, Allison DP, Joy DC, Phelps TJ, Doktycz MJ (2011) Biofabrication of discrete spherical gold nanoparticles using the metal-reducing bacterium Shewanella oneidensis. Acta Biomater 7(5):2148-2152

36. Annamalai A, Christina V, Sudha D, Kalpana M, Lakshmi P (2013) Green synthesis, characterization and antimicrobial activity of $\mathrm{Au}$ NPs using Euphorbia hirta L. leaf extract. Colloids Surf B: Biointerfaces 108:60-65

37. Badwaik VD, Vangala LM, Pender DS, Willis CB, Aguilar ZP, Gonzalez MS, Paripelly R, Dakshinamurthy R (2012) Sizedependent antimicrobial properties of sugar-encapsulated gold nanoparticles synthesized by a green method. Nanoscale Res Lett 7(1): $1-11$

38. Geethalakshmi R, Sarada D (2012) Gold and silver nanoparticles from Trianthema decandra: synthesis, characterization, and antimicrobial properties. Int J Nanomedicine 7:5375

39. Chatterjee S, Bandyopadhyay A, Sarkar K (2011) Effect of iron oxide and gold nanoparticles on bacterial growth leading towards biological application. J Nanobiotechnol 9(1):34 
40. MubarakAli D, Thajuddin N, Jeganathan K, Gunasekaran M (2011) Plant extract mediated synthesis of silver and gold nanoparticles and its antibacterial activity against clinically isolated pathogens. Colloids Surf B: Biointerfaces 85(2):360-365

41. Hernández-Sierra JF, Ruiz F, Pena DCC, Martínez-Gutiérrez F, Martínez AE, Guillén AJP, Tapia-Pérez H, Castañón GM (2008) The antimicrobial sensitivity of Streptococcus mutans to nanoparticles of silver, zinc oxide, and gold. Nanomedicine 4(3):237-240

42. Borah BJ, Yadav A, Dutta DK (2011) Au-nanoparticles: control size and morphology stabilized by tripodal phosphine based ligands and their antimicrobial activity. J Biomed Nanotechnol 7(1):152153

43. Pal S, Mitra K, Azmi S, Ghosh JK, Chakraborty TK (2011) Towards the synthesis of sugar amino acid containing antimicrobial noncytotoxic CAP conjugates with gold nanoparticles and a mechanistic study of cell disruption. Org Biomol Chem 9(13):48064810

44. Nagajyothi P, Sreekanth T, Prasad T, Lee K (2012) Harvesting Au nanoparticles from Carthamus tinctorius flower extract and evaluation of their antimicrobial activity. Adv Sci Lett 5(1):124-130

45. Sreekanth T, Nagajyothi P, Lee KD (2012) Biosynthesis of gold nanoparticles and their antimicrobial activity and cytotoxicity. Adv Sci Lett 6(1):63-69

46. Lokina S, Suresh R, Giribabu K, Stephen A, Sundaram RL, Narayanan V (2014) Spectroscopic investigations, antimicrobial, and cytotoxic activity of green synthesized gold nanoparticles. Spectrochim Acta A Mol Biomol Spectrosc 129:484-490

47. Roy S, Mondal A, Yadav V, Sarkar A, Banerjee R, Sanpui P, Jaiswal A (2019) Mechanistic insight into the antibacterial activity of chitosan exfoliated MoS2 nanosheets: membrane damage, metabolic inactivation, and oxidative stress. ACS Appl Bio Mater 2(7): $2738-2755$

48. Ahmad T, Wani IA, Manzoor N, Ahmed J, Asiri AM (2013) Biosynthesis, structural characterization and antimicrobial activity of gold and silver nanoparticles. Colloids Surf B: Biointerfaces 107: 227-234

49. Wani IA, Ahmad T (2013) Size and shape dependant antifungal activity of gold nanoparticles: a case study of Candida. Colloids Surf B: Biointerfaces 101:162-170
50. Jayaseelan C, Ramkumar R, Rahuman AA, Perumal P (2013) Green synthesis of gold nanoparticles using seed aqueous extract of Abelmoschus esculentus and its antifungal activity. Ind Crop Prod 45:423-429

51. Geethalakshmi R, Sarada D (2013) Characterization and antimicrobial activity of gold and silver nanoparticles synthesized using saponin isolated from Trianthema decandra L. Ind Crop Prod 51:107-115

52. Dennis EK, Kim JH, Parkin S, Awuah SG, Garneau-Tsodikova S (2019) Distorted gold (I)-phosphine complexes as antifungal agents. J Med Chem 63(5):2455-69

53. Jia X, Yao Y, Yu G, Qu L, Li T, Li Z, Xu C (2020) Synthesis of gold-silver nanoalloys under microwave-assisted irradiation by deposition of silver on gold nanoclusters/triple helix glucan and antifungal activity. Carbohydr Polym 238 (2020): 116169

54. Nidhin M, Saneha D, Hans S, Varghese A, Fatima Z, Hameed S (2019) Studies on the antifungal activity of biotemplated gold nanoparticles over Candida albicans. Mater Res Bull 119:110563

55. Amin RM, Mohamed MB, Ramadan MA, Verwanger T, Krammer B (2009) Rapid and sensitive microplate assay for screening the effect of silver and gold nanoparticles on bacteria. Nanomedicine 4(6):637-643

56. Rajathi FAA, Parthiban C, Kumar VG, Anantharaman P (2012) Biosynthesis of antibacterial gold nanoparticles using brown alga, Stoechospermum marginatum (Kützing). Spectrochim Acta A Mol Biomol Spectrosc 99:166-173

57. Nazari ZE, Banoee M, Sepahi AA, Rafii F, Shahverdi AR (2012) The combination effects of trivalent gold ions and gold nanoparticles with different antibiotics against resistant Pseudomonas aeruginosa. Gold Bull 45(2):53-59

58. Hayden SC, Zhao G, Saha K, Phillips RL, Li X, Miranda OR, Rotello VM, El-Sayed MA, Schmidt-Krey I, Bunz UH (2012) Aggregation and interaction of cationic nanoparticles on bacterial surfaces. J Am Chem Soc 134(16):6920-6923

Publisher's Note Springer Nature remains neutral with regard to jurisdictional claims in published maps and institutional affiliations. 